\title{
A Study on the Innovative Mode of Actual Combat Integrated Teaching and Training for the Future
}

\author{
Li Li, Zhao Hongqiang, Sun Weiqi, Zhou Wei, Shi Yumin, Zhang Suqin, \\ Wang Xiaoyan
}

\author{
Naval Aviation University Qingdao Branch, Qingdao, Shangdong, 266041, China \\ Corresponding author: Email: qdxqlixia@163.com
}

\begin{abstract}
It is the premise of integrated teaching and training to set up the idea of actual combat. We must give full play to the advantages of college education and military training, and actively carry out integrated teaching and training. The integrated teaching and training should be closely linked to the requirements of actual combat, focus on the transformation of combat effectiveness generation mode, give full play to the joint efforts of colleges and universities and the army in the training of military talents, and lead the reform of vocational education to further.
\end{abstract}

Key words: actual combat; integrated teaching and training; post education

\section{INTRODUCTION}

It is the new situation of military struggle and the demand of military talents for the current construction and development of the army to carry out integrated teaching and training activities between colleges and universities and the army. It is also an effective way to realize the interconnection of colleges and universities with the army, theory and practice, classroom and battlefield. The essence of combat training is "to train according to the requirements of combat, to fight according to the requirements of training", so as to integrate the training and combat. In order to further implement the requirements of actual combat training, promote the deepening reform of vocational education in military colleges and universities, and improve the quality of military equipment personnel training, integrated teaching and training activities need to continuously strengthen the communication and cooperation between colleges and forces, optimize the integration of resources, give full play to complementary advantages, build a platform for expanding teaching practice, gradually improve the relevant operation mechanism, strive to explore the method system of integrated teaching and training, and promote the training of high-quality talents, and promote the high integration of teaching and training, comprehensive exercises and actual combat training of troops ${ }^{[1-2]}$.

\section{THE SIGNIFICANCE OF INTEGRATED TEACHING AND TRAINING}

\subsection{Integrated teaching and training is an important way to train new high-quality military talents}

Integrated teaching and training is a key measure for vocational education colleges to implement the requirements of practical operation, vigorously cultivate applied military talents, and achieve joint education with the army. It is an important means to promote the transformation of military talents' knowledge to ability, an inevitable choice to promote the reform of teaching and training mode in colleges and universities, and a main channel to promote the integration and communication between colleges and the army. Through integrated teaching and training, we can give full play to the complementary advantages of talent training and military training resources in colleges and universities, realize the effective connection between teaching and military training in colleges and universities, and achieve the goal of training talents together, improving together and win-win results for both sides ${ }^{[3]}$.

\subsection{Joint teaching and training is the actual need of exerting the teaching resource efficiency of military equipment}

Colleges and universities and troops carry out integrated teaching and training, which can use the resources advantages of the army to provide students with practice 
places, solve the difficulties in practice and training conditions in the teaching of colleges and universities, effectively make up for the lack of new equipment in colleges and universities temporarily, ensure that students can carry out training in equipment maintenance, detection and troubleshooting, and enable that the colleges, equipment development and production units and troops can be used to the maximum and give full play to the best efficiency of teaching resources.

\subsection{Integrated teaching and training is an effective way to improve the post holding ability of cadets}

Military colleges and universities are the main channels for equipment personnel training. Integrated teaching and training emphasizes that it is guided by the needs of the army, close to the actual situation of the army, close to the requirements of posts, close to combat training, close to the development of equipment. In order to achieve the seamless connection between college education and military training, and enable students to be competent for the post work of the army as soon as they graduate, it is necessary to build a integrated teaching and training mechanism between the classroom and the training field, extend the classroom to the battlefield and the training ground to the drill ground. Therefore, in order to realize the two-way interaction between college education and army training, and promote the transformation of theoretical knowledge to professional ability, it is necessary to reform the integrated teaching and training mode, dynamically update the teaching content, enrich the teaching methods and means, effectively enhance the pertinence of teaching, and finally achieve the perfect unity of teaching objectives and training objectives.

\section{THE MAIN MEASURES TO GRASP ACCURATELY, EXPLORE SCIENTIFICALLY, AND STRENGTHEN THE INTEGRATED TEACHING AND TRAINING OF TALENTS BETWEEN COLLEGES AND ARMY}

Integrated teaching and training is not only the requirement of the times for college teaching and military training, but also an effective way to improve the quality of military personnel training. According to the characteristics of integrated teaching and training, it is necessary to integrate, optimize, systematically design, scientifically build a platform of integrated teaching and training resources and various management mechanisms, strengthen the construction of integrated teaching and training courses, improve the content and methods of teaching and training, and make colleges and universities more closely linked with the army, cooperate more effectively and work more efficiently, so as to promote the sound development of integrated teaching and training.

$$
\begin{aligned}
& \text { 3.1. Grasp the law, plan systematically and } \\
& \text { optimize the design }
\end{aligned}
$$

\subsubsection{Find out the location and recognize the characteristics and laws}

In order to create a benign interactive system of integrated teaching and training, it is necessary to scientifically fix a position the role of colleges and forces in integrated teaching and training, reasonably formulate the long-term planning and stage objectives of integrated teaching and training. From the perspective of the cognitive law of learning, both follow the process from easy to difficult, from simple to complex, from basic to application, from knowledge to ability. In terms of the implementation steps of training, colleges and universities usually arrange courses according to the order of first basic post and then post, while the army training usually carries out courses according to the content requirements of the training program. Therefore, it is necessary to strengthen the optimization design of the macro system and promote the overall and orderly development of integrated teaching and training ${ }^{[4]}$.

\subsubsection{Take in everything and make a reasonable overall plan}

Unified planning is an important guarantee for integrated teaching and training to culture military personnel. In order to realize the effective connection between personnel training and military equipment resources, it is necessary to solve all kinds of bottlenecks restricting the integrated teaching and training activities of colleges and universities and the army, that is, how to face the army, adhere to the actual combat, share talents, share resources, share achievements and other issues. At the same time, both sides should form a joint force in organization and leadership, establish a coordinated and smooth joint training mechanism, and strive to provide strong theoretical and technical support for talent training.

\subsubsection{Demand driven and focus on the post ability}

The core and key of integrated teaching and training is to strengthen the course construction, optimize the content of teaching and training, and build the content system of integrated teaching and training. We should take colleges and troops as an organic whole of personnel training, start with their respective characteristics, laws and training practices, scientifically establish training courses and design teaching and training contents as a whole, so as to 
systematically build a joint teaching and training content system with distinct characteristics and strong pertinence. We should closely focus on the goal of training the post holding ability of the army, adhere to the requirements of equipment practice, accelerate the course reorganization, optimize the course structure, and update the teaching content.

\subsection{Grasp common management, create platform and strengthen guarantee}

At present, based on the demand of information construction for talent team, colleges and forces should fully rely on the achievements of information construction of our army, deeply integrate and tap the potential of military education resources, and actively build a platform for integrated teaching and training of talents.

\subsubsection{Integration of resources and establishment of information platform for resource sharing}

In order to solve the problems of many units of integrated teaching and training and the difficulty of supporting, and to improve the information utilization rate of colleges and forces, we must break the traditional situation of information isolation and self-contained system, realize the integration of elements and functions, and build the information of teaching, scientific research and training needed for joint training in accordance with the principles of existing, mutually beneficial sharing, scientific standardization, intensive and efficient support platform, combined with the characteristics of integrated teaching and training of colleges and forces, to enhance the quality and efficiency of integrated teaching and training. Focusing on the goal of improving the quality and ability of military talents, we should make full use of the penetration, integration and connectivity of information technology to build an information platform for integrated teaching and training, gradually integrate all kinds of integrated teaching and training support forces, support units and support elements into an organic whole, improve the support ability of integrated teaching and training, and continuously promote the in-depth development of integrated teaching and training information construction [5].

\subsubsection{Give full play to advantages and establish a practical platform for joint training}

Due to the limitation of objective conditions, there is still a certain gap between the actual combat training and the actual situation of the army, while the army, although all kinds of practical equipment and training conditions are superior to the university, lacks a scientific system, rigorous and meticulous teaching resource platform. Therefore, we should give full play to the respective advantages of colleges and universities and the army, integrate advanced training methods and complete training venues, establish practical teaching and training bases, achieve the organic unity of the teaching content of colleges and universities and the training subjects of the army, so that colleges and universities and the army can organize joint training, practical training and other activities, and improve the effect of joint training in the combination of training.

\subsection{Perfect mechanism, scientific management and efficient operation}

\subsubsection{Clarify the division of labor and establish the cooperation mechanism of integrated teaching and training}

Colleges and universities have a solid professional foundation of teachers and a systematic and rigorous teaching plan and teaching material construction system, while the army has certain advantages in practical operation and practical exercises. Therefore, colleges and universities and the army should establish a well-managed, well-organized and mutual support and cooperate with a harmonious joint teaching and training cooperation organization, set up a joint teaching group by disciplines, specialties and levels to prepare lessons collectively, implement by categories and check jointly, ensure the deep integration of knowledge and skills of the college system and rich practical experience of the army, and ensure the smooth development of integrated teaching and training ${ }^{[6]}$.

\subsubsection{Integration of resources and establishment of integrated teaching and training guarantee mechanism}

A good and unified guarantee mechanism can improve the theoretical basis of integrated teaching and training. In order to ensure the efficient and stable development of the integrated teaching and training, it should be established that a joint support organization composed of colleges and relevant personnel of the army. According to the support needs of the integrated teaching and training, a reasonable support plan should be made, and the support standards should be accurately formulated. Both colleges and universities and the army should jointly implement and work together to strengthen the construction of relevant supporting facilities, and strive to improve the equipment resources of the training base to meet the different needs of the integrated teaching and training with a high sense of responsibility and mission to complete the security task together. 


\subsubsection{Strict system and establishment of joint training and assessment mechanism}

In order to test the training effect of integrated teaching and training, it is necessary to formulate a set of assessment standard rules with clear principles, specific indicators, objective evaluation and strong operability, so as to form a joint assessment mechanism between colleges and troops. In terms of assessment standards, we should not only keep up with the development of the Navy's mission of "going to dark blue", but also focus on the requirements of the post holding ability of the army, with emphasis on the standardization of assessment. In terms of assessment content, we should take the equipment laws and regulations, talent training plan and teaching plan as the assessment basis, organize the army and experts of colleges and universities to set up a joint assessment team, take the combination of directional assessment and random assessment to carry out joint examination, highlight the professional skills and ability quality of students, urge the quality of integrated teaching and training through assessment, so as to promote the reform of promoting learning by examination and training by examination purport

\section{CONCLUSION}

Integrated teaching and training is the product of the innovation and development of post education in military colleges and universities. It is also an effective way to cultivate talents under the condition of information technology in our army. The smooth development of integrated teaching and training can effectively ensure that college education is closely related to the needs of combat training, military construction and development, and job requirements of trainees.

\section{ACKNOWLEDGMENT}

This paper was supported by education reform project of Naval Aviation University.

\section{REFERENCES}

[1] Jiaoyang Zheng, Haiyan Chen, et al. "Integrated Teaching and Training" Training Mode of Vocational Education [J]. Journal of PLA Hospital management, 2018,25 (08): 771-772.

[2] Huaizhou Zheng, Exploration on "Integrated Teaching and Training" Training mode of Equipment Talents [J]. Journal of equipment college, 2013,2 (1): $1-5$.

[3]Yun Shi, Xiangbin Chen, et al. Thoughts on
Promoting the In-depth Development of Integrated Teaching and Training between Colleges and Military Forces [J]. Journal of Military Transportation College, 2015,5 (5): 75-78.

[4] Wensheng Wang, Weidong Liu, et al. Accurate Grasp of the Common Requirements of Integrated Teaching and Training between Colleges and Army [J]. Journal of Higher Education Rresearch, 2013,12 (4): 26-28.

[5]Jun Zhang, Songshan Sun, et al. Facing the Future, United Education [J]. Social Sciences, 2011,1 (1): 144-145.

[6]Changhai Li, Xiaochun Tian. Analysis on the Way of Integrated Teaching and Training in Assembly Colleges [J]. Journal of Equipment College, 2013,12 (6): 9-12. 